Check for updates

Cite this: RSC Adv., 2017, 7, 29927

Received 27th April 2017

Accepted 3rd June 2017

DOI: 10.1039/c7ra04751g

rsc.li/rsc-advances

\title{
Dual role of polyphosphoric acid-activated nitroalkanes in oxidative peri-annulations: efficient synthesis of 1,3,6,8-tetraazapyrenes $\dagger$
}

\author{
Alexander V. Aksenov, (D) *a Dmitrii S. Ovcharov, ${ }^{a}$ Nicolai A. Aksenov, ${ }^{a b}$ \\ Dmitrii A. Aksenov, ${ }^{a}$ Oleg N. Nadein ${ }^{a}$ and Michael Rubin (D) *ac
}

\begin{abstract}
A highly efficient synthetic method for expeditious and selective assembly of tetraazopyrenes (TAPy) is reported, based on the novel reaction of electrophilically activated nitroalkanes with aromatic amines. Remarkably, the nitroalkanes play a dual role in this process, also serving as mild and efficient oxidants promoting aromatization of the final product and allowing for the exclusion of a poorly controllable aerobic treatment.
\end{abstract}

\section{Introduction}

During the past decade, increasing attention of many research groups has been placed on the development of new $\pi$-conjugated organic materials for application in electronic and optoelectronic devices, such as light-emitting diodes (LEDs), fieldeffect transistors (FETs), and efficient and cost-effective solar cells. $^{\mathbf{1 , 2}}$ Among other fused polycyclic systems, tetraazapyrenes (TAPy, 1) have great promise as novel luminescent materials in sensors, lasers, and semi-conductor devices due to their favorable Red-Ox and photochemical properties. ${ }^{3}$ However, synthetic approaches to this heterocyclic core are limited to a handful of reliable methods. The most common synthetic route employs a double-fold cyclo-condensation of naphthalene-1,4,5,8-tetraamine (2) with carboxylic anhydrides and subsequent oxidation of the intermediate 1,8-dihydropyrimido[4,5,6-gh]perimidines 3 (Scheme 1, method A). ${ }^{3 a, b}$ Alternatively, this protocol could utilize $1 H$-perimidine-6,7-diamines $4(\text { method } \mathrm{B})^{4}$ that are readily accessible via Pozharskii's electrophilic nitration approach. ${ }^{4}$ More unusual approaches involve thermally induced double-fold cyclo-condensation of 5,8bis(methylamino)naphthalene-1,4-diones (5) (Scheme 1, method C), ${ }^{5}$ or oxidative decomposition of dinuclear copper$2,2^{\prime}, 2^{\prime \prime}, 2^{\prime \prime \prime}$-(naphthalene-1,4,5,8-tetrayl)tetraguanidine complexes 6 (method D). ${ }^{6}$ Notably, all of these methods rely on an

${ }^{a}$ Department of Chemistry, North Caucasus Federal University, 1a Pushkin St., Stavropol 355009, Russian Federation.E-mail: alexaks05@rambler.ru

${ }^{b}$ Department of Organic Chemistry, People's Friendship University of Russia (RUDN University), 6 Miklukho-Maklaya St., Moscow, 117198, Russian Federation

${ }^{c}$ Department of Chemistry, University of Kansas, 1251 Wescoe Hall Dr., Lawrence, KS 66045-7582, USA. E-mail: mrubin@ku.edu; Fax: +1-785-864-5396; Tel: +1-785-8645071

$\dagger$ Electronic supplementary information (ESI) available: Spectral and crystallographic data. CCDC 1544322. For ESI and crystallographic data in CIF or other electronic format see DOI: 10.1039/c7ra04751g oxidation step (usually aerobic) that could be substratedependent, providing inconsistent results upon scaling up. Herein we wish to report an innovative approach to the TAPy scaffolds, utilizing the nucleophilic reaction of substrates 2 and 4 with umpolung-activated electrophilic nitroalkanes. Remarkably, the latter compounds also serve as oxidizing agents for the aromatization of the target heterocyclic system.

\section{Results and discussion}

For several years our group had a great interest in development novel synthetic approaches towards fused aromatic polyheterocyclic cores targeting material science ${ }^{7}$ and medicinal chemistry applications. ${ }^{8}$ Several innovative approaches towards TAPy scaffolds were also developed (Scheme 2). These methods involved one-pot double nitration of perimidines followed by zinc-assisted reductive cyclo-condensation with formic acid (method E), ${ }^{9}$ and various peri-annulation cascades triggered by

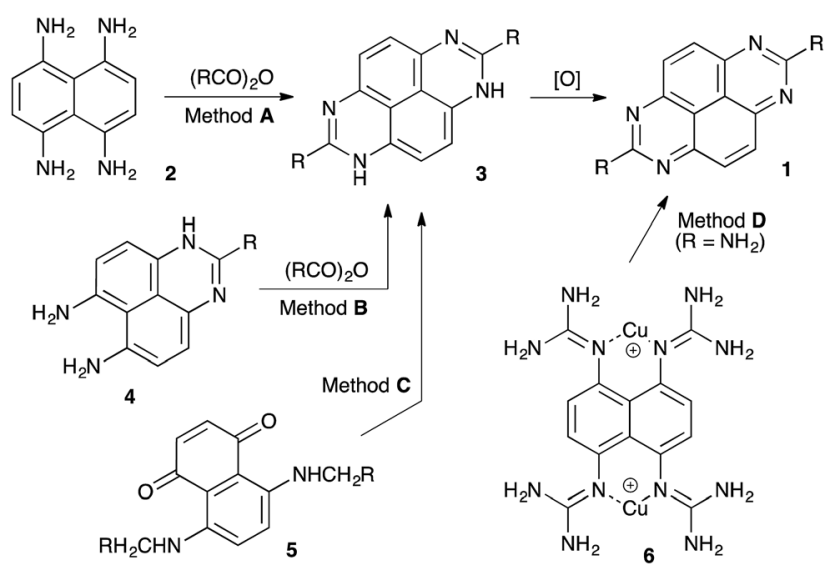

Scheme 1 
<smiles>[R]C1=Nc2ccc([N+](=O)[O-])c3c([N+](=O)[O-])ccc(c23)N1</smiles><smiles>[R]C(=O)Nc1ccc2c3c(cccc13)NC(P)=N2</smiles><smiles>[R]c1nc2ccc3nc([R])nc4ccc(n1)c2c34</smiles>

Scheme 2

the Schmidt reaction of 6(7)-acylperimidines 8 (Scheme 2) (method F). ${ }^{10}$ We also demonstrated that nitroalkanes 10 react with polyphosphoric acid (PPA) to form highly stabilized aci form 11, which can serve as electrophilic component in highly selective Nef-like processes involving various carbon-11 and nitrogen-based nucleophiles ${ }^{\mathbf{1 2}}$ (Scheme 3). Indeed, reactions of 11 with electron-rich aromatic compounds usually affords phosphorylated $N$-hydroxyhydroxylamine species 12 , possessing a hydrogen atom at $\alpha$-position, which undergoes facile elimination of $\mathrm{H}_{3} \mathrm{PO}_{4}$ to furnish phosphorylated oxime 10. The latter can undergo further Beckman or aza-Wagner-Meerwein rearrangements providing unusual avenues for selective installation of functional groups into aromatic compounds (Scheme 3). ${ }^{\mathbf{1 3}}$ Reactions of $\mathbf{1 1}$ with nitrogen-based nucleophiles (typically anilines) provide stabilized amidinium ions $\mathbf{1 4}$. Installation of nucleophilic functionality in the strategic position could trigger intramolecular cyclo-condensation. This approach allowed us to develop expeditious synthetic route towards imidazoles 15 and oxazoles 16 (Scheme 3). ${ }^{14}$ We envisioned that similar strategy could potentially be employed for

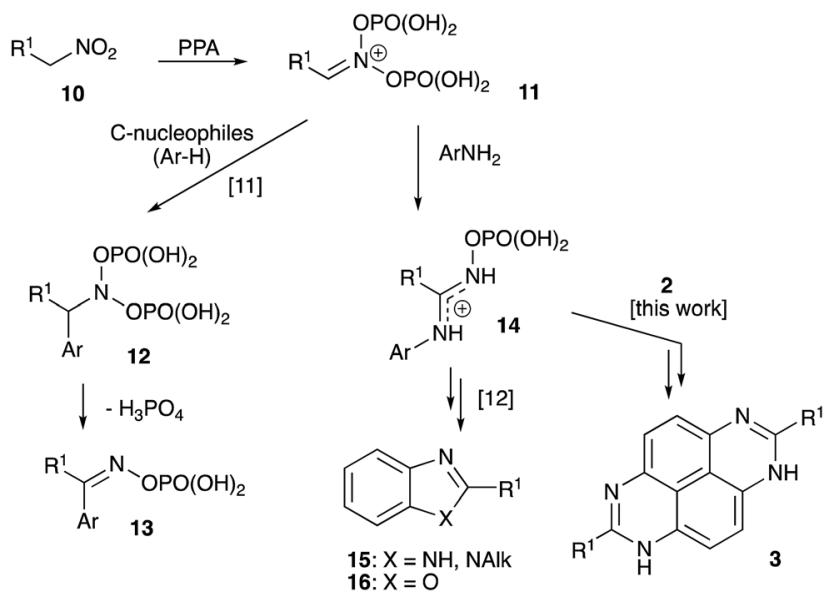

Scheme 3

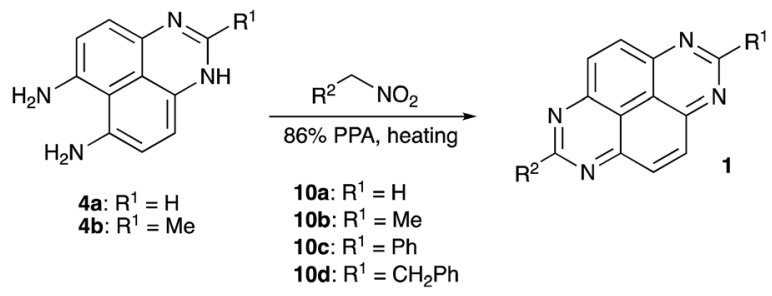

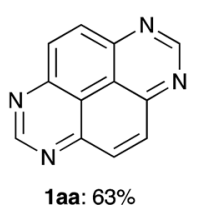<smiles>[Y16]c1nc2ccc3ncnc4ccc(n1)c2c34</smiles><smiles>Cc1nc2ccc3nc(C)nc4ccc(n1)c2c34</smiles>

1ab: $72 \%$ (from $4 a$ and $10 b$ ) $63 \%$ (from $4 b$ and $10 a$ )

1bb: $78 \%$<smiles>c1ccc(-c2nc3ccc4ncnc5ccc(n2)c3c45)cc1</smiles>

1ac: $72 \%$ (from $4 a$ and 10c)<smiles>Cc1nc2ccc3nc(-c4ccccc4)nc4ccc(n1)c2c34</smiles>

1bc: $71 \%$<smiles>c1ccc(Cc2nc3ccc4ncnc5ccc(n2)c3c45)cc1</smiles>

1ad: $63 \%$

(from $4 a$ and $10 d$ )

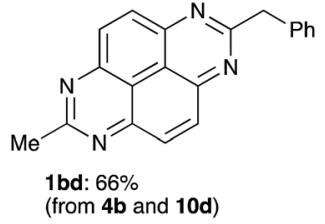

Scheme 4

the synthesis of heteroaromatic core 3 (Scheme 3) via reaction of nitroalkanes with $1 H$-perimidine-6,7-diamines 4.

To test this idea we stirred $1 \mathrm{H}$-perimidine-6,7-diamine (4a) in 86\% PPA in the presence of nitromethane (10a). Interestingly, we did not observe formation of compound $3\left(\mathrm{R}^{1}=\mathrm{H}\right)$. Instead, TAPy (1aa) formed as sole product in a yield of $63 \%$ (Scheme 4 ). Due to the symmetry of the scaffold, 2-Me-TAPy (1ab) can be assembled in two different way, either starting from $\mathbf{4 a}$ and nitroethane (10b) or by combining 2-methyl- $1 H$-perimidine-6,7diamine (4b) with nitromethane (10a). Both protocols work fine, affording the corresponding product 1ab in $72 \%$ and $63 \%$ yield, respectively (Scheme 4). 2,7- $\mathrm{Me}_{2}$-TAPy (1bb) was synthesized in a similar manner by treatment of $\mathbf{4 b}$ with nitroethane $(\mathbf{1 0 b})$. Evidently, a phenyl substituent could be introduced into the target scaffold via the reaction of an appropriate perimidine with $\alpha$-nitrotoluene (10c). Indeed, 2-Ph-TAPy (1ac) and 2-Me-7PhTAPy (1bc) were accessed via this mode very efficiently (Scheme 4). Finally, (2-nitroethyl)-benzene (10d) can be employed for the installation of benzylic substituents. Both tested perimidines $\mathbf{4 a}$ and $\mathbf{4} \mathbf{b}$ afforded the corresponding 7benzyl-TAPy's 1ad and 1bd in good yields (Scheme 4).

As mentioned above, the tetraazopyrenes 1 were obtained in the featured reaction with nitroalkanes directly, and reduced form 3 was never detected in the reaction mixtures. This also was the case even when the annulations were carried out under inert atmosphere to exclude the possibility of aerobic oxidation. We reasoned, that the nitroalkane aci formmay play here a dual 


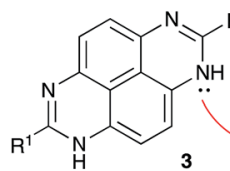

3<smiles>CCC(C)[N+]([O-])OOOOC</smiles>

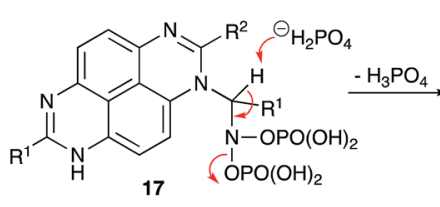<smiles>[R]c1nc2ccc3c4c2c(ccc4n3C(=NOC(=O)O)NCBr)n1CBr</smiles><smiles>[R]c1nc2ccc3nc([R])nc4ccc(n1)c2c34</smiles>

Scheme 5

role, serving both as an electrophilic reagent in cyclization and as an oxidant. Indeed, if we suppose that 1,8-dihydropyrimido $[4,5,6-g h]$ perimidine core 3 was formed in the reaction, it also could be involved in nucleophilic attack at the $\mathrm{C}=\mathrm{N}$ bond of $a c i$ form 11. The resulting $N$-(imino-methyl)amidine 18 would then experience deprotonation of a distal $\mathrm{N}-\mathrm{H}$ bond triggering elimination of phosphoric acid and nitrile $\mathbf{1 9}$ and leading to aromatization of the heterocyclic core of $\mathbf{1}$ (Scheme 5) (Fig. 1).

It should be pointed out that in acidic medium, nitrile 19 exists in equilibrium with highly electrophilic protonated form 20 (Scheme 6). We believe that this form might be responsible for the featured peri-annulation process according to the mechanism described in Scheme 6. Indeed, nucleophilic attack of the aniline moiety in perimidine 4 should afford amidinium species 21, which should exist in equilibrium with form $\mathbf{2 2}$. Subsequent 6-exo-trig nucleophilic ring closure should provide diaminomethanaminium moiety 23, that could experience a proton transfer to arrange an exo-cyclic ammonium leaving group in structure 24. Finally, elimination of ammonia would afford cyclic amidinium 25, which, after deprotonation, would provide 1,8-dihydropyrimido[4,5,6-gh]perimidine structure 3 (Scheme 6). The latter would be again oxidized by nitroalkanes

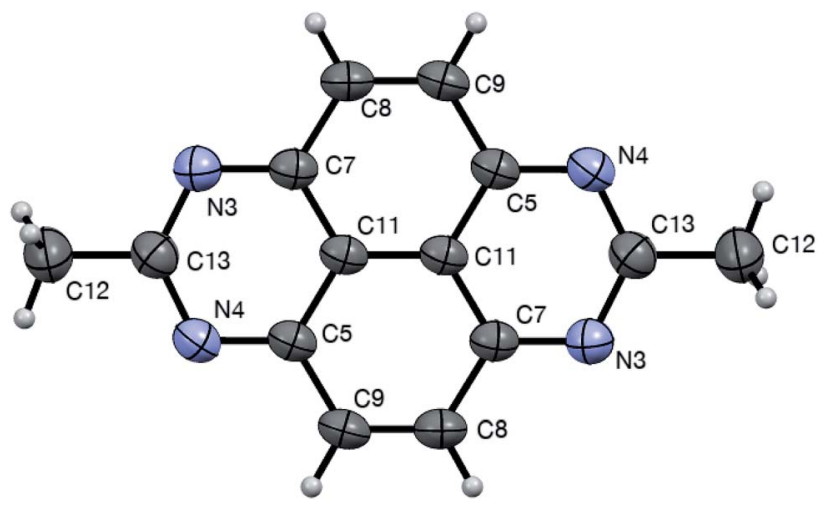

Fig. 1 ORTEP drawing od crystal structure of compound 1bb (CCDC $1544322 \dagger$ ) showing atom numbering labels and 50\% probability amplitude displacement ellipsoids.

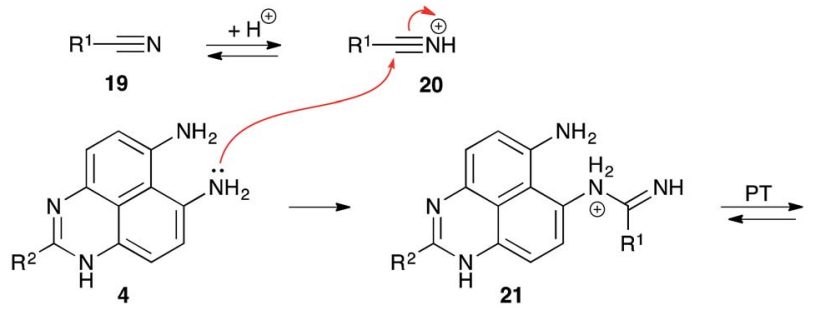

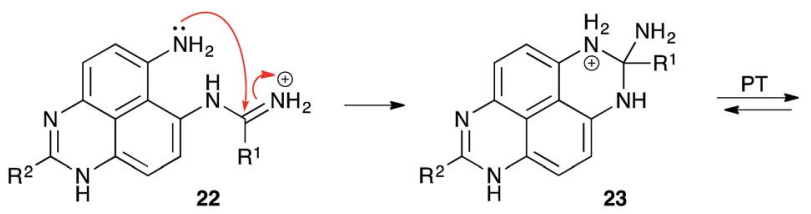<smiles>[R7]C1=Nc2ccc3c4c(ccc(c24)N1)NC([Y9])NC3</smiles>

Scheme 6

into TAPy (1), as described in Scheme 5, and during this process nitrile 19 would be regenerated.

The following empirical observation strongly supports this mechanistic hypothesis. Firstly, trace amounts of phenylacetonitrile were detected by GC and HRMS in reactions mixtures involving nitroalkane 10d. Secondly, peri-annulation of compound $\mathbf{4 b}$ with acetonitrile (instead of nitroethane) proceeded under similar reaction conditions (inert atmosphere was used to minimize aerobic oxidation) affording mixtures of $\mathbf{3 b} \mathbf{b}$ and small amounts of $\mathbf{1 b b}$ (the latter was presumably formed due to oxidation during isolation). Thirdly, this mixture was quickly transformed into pure $\mathbf{1 b b}$ after treatment with nitroethane in $86 \%$ PPA.

Having in hand such an efficient protocol for the synthesis of TAPy structures 1 from permidine precursors 4 , we reserved the efforts to expand this methodology into a double-fold cyclocondensation; simultaneously installing two six-membered heterocyclic rings on the naphthalene-1,4,5,8-tetraamine (2). To test this idea we treated a solution of tetraamine 2 in $86 \%$ PPA with an excess of nitroalkane $(\mathbf{1 0 a}, \mathbf{1 0 b}$, or 10c) at 100$150{ }^{\circ} \mathrm{C}$ (see Experimental part for details). Gratifyingly, the desired process proceeded smoothly, affording the corresponding symmetric TAPy structures (1aa, $\mathbf{1 b b}$, or 1cc, respectively) as sole products, although only in medium yields (Scheme 7).

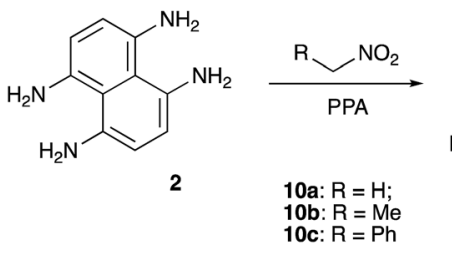<smiles>[R]c1nc2ccc3nc([R])nc4ccc(n1)c2c34</smiles>

Scheme 7 


\section{Conclusions}

In conclusion, we have developed highly efficient and chemoselective method for the synthesis of tetraazapyrenes (TAPy) based on the reaction of $1 \mathrm{H}$-perimidine-6,7-diamines or naphthaene-1,4,5,8-tetraamine with nitroalkanes. This reaction demonstrates a very curious example of PPA-assisted activation of nitroalkane species towards nucleophilic attack. Interestingly, the electrophilically activated nitroalkane also plays a role of mild and efficient oxidant, providing direct access to the TAPy aromatic core and allowing excluding poorly controllable aerobic oxidation step.

\section{Experimental part}

${ }^{1} \mathrm{H}$ and ${ }^{13} \mathrm{C}$ NMR (DEPT-Q) spectra were recorded on a Bruker Avance-III spectrometer (400 or $100 \mathrm{MHz}$, respectively) equipped with $\mathrm{BBO}$ probe in $\mathrm{CDCl}_{3}$, using TMS as an internal standard. The abbreviation " $\psi \mathrm{t}$ " is used in listed spectra for doublets of doublets with non-resolved central lines. High-resolution mass spectra were registered with a Bruker Maxis spectrometer (electrospray ionization, in $\mathrm{MeCN}$ solution, using $\mathrm{HCO}_{2} \mathrm{Na}-$ $\mathrm{HCO}_{2} \mathrm{H}$ for calibration). Melting points were measured with a Stuart smp30 apparatus. All reactions were performed in ovendried $5 \mathrm{~mL}$ Erlenmeyer flasks (that can be open to the atmosphere), employing overhead stirring. Reaction progress and purity of isolated compounds were monitored by TLC on Silufol UV-254 plates. Perimidines $\mathbf{4 a - b}$ (in the form of trihydrochlorides), ${ }^{4}$ hexachlorostannate of tetraaminonaphthalene $2,{ }^{3 b}$ and nitroalkenes $\mathbf{1 0 b}, \mathbf{c}^{\mathbf{1 3}}$ were prepared according to the literature procedures. All other reagents and solvents were purchased from commercial vendors and used as received.

\section{General procedure for preparation of 1,3,6,8-tetraazapyrenes from $1 \mathrm{H}$-perimidine-6,7-diamines $(\operatorname{method} \mathrm{A})$}

Reaction vessels charged with diaminoperimidine trihydrochloride (0.5 mmol), nitroalkane $(1.0 \mathrm{mmol})$, and polyphosphoric acid $\left(86 \% \mathrm{P}_{2} \mathrm{O}_{5}, 1.5 \mathrm{~g}\right)$ were vigorously stirred and heated at appropriate temperature $\left(14 \mathrm{~h}\right.$ at $100{ }^{\circ} \mathrm{C}$ for reactions involving nitromethane; $3 \mathrm{~h}$ at $110{ }^{\circ} \mathrm{C}$ for nitroethane, and $8 \mathrm{~h}$ $150{ }^{\circ} \mathrm{C}$ for phenylnitromethane and phenylnitroethane, respectively). Initially, intense foaming of the mixture was observed, which seized as the process progressed. Upon completion of the reaction, the mixture was poured into cold water $(50 \mathrm{~mL})$, neutralized with aqueous ammonia, extracted with ethyl acetate $(5 \times 70 \mathrm{~mL})$, and concentrated in vacuum. Compounds 1aa, 1ab, 1bb can be obtained in pure form after trituation of the residue in dichloromethane $(1 \mathrm{~mL})$ and subsequent filtration. The filtrate was concentrated and purified by flash column chromatography eluting with ethyl acetate to obtain an additional crop of material (about 15-20\%). For all other compounds, combined ethyl acetate extracts were concentrated and the residual material was purified by preparative column chromatography on silica gel eluting with ethyl acetate.
General procedure for preparation of 1,3,6,8-tetraazapyrenes from naphthalene-1,4,5,8-tetraamine (method $B$ )

This protocol is identical to the one described above (method A), except for employing a mixture of naphthalene-1,4,5,8tetraamine 2 (in the form of the stable hexachlorostannate that can be taken directly from reduction of the corresponding nitroarenes $)^{3 b, 14}(0.261 \mathrm{~g}, 0.5 \mathrm{mmol})$, nitroalkane $(2.0 \mathrm{mmol})$, and polyphosphoric acid $\left(86 \% \mathrm{P}_{2} \mathrm{O}_{5}, 2.5 \mathrm{~g}\right)$.

\section{Pyrimido $[4,5,6-g h]$ perimidine $(1 \mathrm{aa})^{10,15}$}

This material was obtained as a yellowish crystalline solid, $\mathrm{mp}$ over $300{ }^{\circ} \mathrm{C}, \mathrm{R}_{\mathrm{f}} 0.15$ (10\% EtOH/EtOAc); yield $65 \mathrm{mg}$ (0.32 mmol, $63 \%$ - via method A; $58 \mathrm{mg}$ (0.28 mmol, 56\%) - via method B; ${ }^{1} \mathrm{H} \mathrm{NMR}\left(\mathrm{CDCl}_{3}\right) \delta$, ppm: $10.08(\mathrm{~s}, 2 \mathrm{H}), 8.71(\mathrm{~s}, 4 \mathrm{H}) ;{ }^{13} \mathrm{C} \mathrm{NMR}$ $\left(\mathrm{CDCl}_{3}\right) \delta$, ppm: 158.0 (2C), 152.8 (4C), 136.5 (4C), 114.2 (2C); IR $\left(\mathrm{NaCl}, \mathrm{cm}^{-1}\right): 3050,1603,1437,1240,1180,965,843,712$; HRMS (ES TOF) calcd for $\mathrm{C}_{12} \mathrm{H}_{7} \mathrm{~N}_{4}(\mathrm{M}+\mathrm{H})^{+}: 207.0665$, found 207.0660 (2.4 ppm).

\section{2-Methylpyrimido[4,5,6-gh]perimidine $(1 \mathrm{ab})^{10}$}

This material was obtained as a yellowish crystalline solid, $\mathrm{mp}$ over $300{ }^{\circ} \mathrm{C}, R_{\mathrm{f}} 0.21$ (10\% EtOH/EtOAc); yield $79 \mathrm{mg}$ (0.36 mmol, $72 \%$ ) - via method A in reaction of $4 a$ with $10 b ; 69 \mathrm{mg}$ $(0.32 \mathrm{mmol}, 63 \%)$ - in reaction of $4 \mathbf{b}$ with $10 a ;{ }^{1} \mathrm{H} \mathrm{NMR}\left(\mathrm{CDCl}_{3}\right)$ $\delta$, ppm: 9.92 (s, 1H), 8.51 (d, $J=9.5 \mathrm{~Hz}, 2 \mathrm{H}), 8.45$ (d, $J=9.5 \mathrm{~Hz}$, 2H), 3.17 (s, 3H); ${ }^{13} \mathrm{C} \mathrm{NMR}\left(\mathrm{CDCl}_{3}\right) \delta$, ppm: 168.6, 155.8, 154.7 (2C), 152.4 (2C), 137.1 (2C), 135.2 (2C), 113.7 (2C), 25.3; IR ( NaCl, $\mathrm{cm}^{-1}$ ): 3057, 1562, 1551, 1478, 1491, 1355, 1342, 856; HRMS (ES TOF) calcd for $\mathrm{C}_{13} \mathrm{H}_{9} \mathrm{~N}_{4}(\mathrm{M}+\mathrm{H})^{+}: 221.0822$, found 221.0825 (1.4 ppm).

\section{2,7-Dimethylpyrimido[4,5,6-gh]perimidine $(1 \mathrm{bb})^{11 b}$}

This material was obtained as a yellowish crystalline solid, $\mathrm{mp}$ over $300{ }^{\circ} \mathrm{C}, R_{\mathrm{f}} 0.25$ (10\% EtOH/EtOAc); yield $91 \mathrm{mg}$ (0.39 mmol, 78\%) - via method A; $69 \mathrm{mg}$ (0.30 mmol, 59\%) - via method B; ${ }^{1} \mathrm{H}$ NMR $\left(\mathrm{CDCl}_{3}\right) \delta$, ppm: $8.35(\mathrm{~s}, 4 \mathrm{H}), 3.03(\mathrm{~s}, 6 \mathrm{H}) ;{ }^{13} \mathrm{C}$ NMR $\left(\mathrm{CDCl}_{3}\right) \delta$, ppm: 166.9 (2C), 152.3 (4C), 135.6 (4C), 111.6 (2C), 26.8 (2C); IR ( $\mathrm{NaCl}, \mathrm{cm}^{-1}$ ): 3055, 1569, 1558, 1493, 1485, 1361, 1347, 858; HRMS (ES TOF) calcd for $\mathrm{C}_{14} \mathrm{H}_{11} \mathrm{~N}_{4}(\mathrm{M}+\mathrm{H})^{+}$: 235.0978, found 235.0983 (2.1 ppm).

\section{2-Phenylpyrimido[4,5,6-gh]perimidine $(1 \mathrm{ac})^{11 a}$}

This material was obtained as a yellowish crystalline solid, $\mathrm{mp}$ over $300{ }^{\circ} \mathrm{C}, \quad R_{\mathrm{f}} 0.63 \quad(10 \%$ EtOH/EtOAc); yield $102 \mathrm{mg}$ (0.36 mmol, 72\%) - via method A in reaction of $4 \mathbf{c}$ with $10 a ;{ }^{1} \mathrm{H}$ NMR $\left(\mathrm{CDCl}_{3}\right) \delta$, ppm: $9.66(\mathrm{~s}, 2 \mathrm{H}), 8.81(\mathrm{~d}, J=8.3 \mathrm{~Hz}, 2 \mathrm{H}), 8.57$ $(\mathrm{d}, J=9.5 \mathrm{~Hz}, 2 \mathrm{H}), 8.52(\mathrm{~d}, J=9.5 \mathrm{~Hz}, 2 \mathrm{H}), 7.64-759(\mathrm{~m}, 3 \mathrm{H}) ;{ }^{13} \mathrm{C}$ NMR $\left(\mathrm{CDCl}_{3}\right) \delta$, ppm: 165.9, 155.4, 154.7 (2C), 152.4 (2C), 138.4, 137.2 (2C), 135.2 (2C), 133.0, 131.2 (2C), 129.3 (2C), 114.2, 112.7; FT IR (NaCl, $\mathrm{cm}^{-1}$ ): 3052, 1577, 1555, 1499, 1483, 861, 723, 641; HRMS (ES TOF) calcd for $\mathrm{C}_{18} \mathrm{H}_{11} \mathrm{~N}_{4}(\mathrm{M}+\mathrm{H})^{+}: 283.0978$, found 283.0971 (2.5 ppm). 
2-Methyl-7-phenylpyrimido[4,5,6-gh]perimidine (1bc $)^{11 b}$

This material was obtained as a yellowish crystalline solid, mp over $300{ }^{\circ} \mathrm{C}, \quad R_{\mathrm{f}} 0.75 \quad(10 \% \quad$ EtOH/EtOAc); yield $105 \mathrm{mg}$ (0.36 mmol, 71\%) - via method A in reaction of $4 \mathbf{b}$ with $10 \mathbf{c} ;{ }^{1} \mathrm{H}$ NMR $\left(\mathrm{CDCl}_{3}\right) \delta$, ppm: $8.84(\mathrm{~d}, J=8.3 \mathrm{~Hz}, 2 \mathrm{H}), 8.66(\mathrm{~d}, J=9.5 \mathrm{~Hz}$, $2 \mathrm{H}), 8.56(\mathrm{~d}, J=9.5 \mathrm{~Hz}, 2 \mathrm{H}), 7.61(\psi \mathrm{t}, 1 \mathrm{H}), 7.55(\mathrm{~d}, J=7.4 \mathrm{~Hz}$, $2 \mathrm{H}), 3.24(\mathrm{~s}, 3 \mathrm{H}) ;{ }^{13} \mathrm{C} \mathrm{NMR}\left(\mathrm{CDCl}_{3}\right) \delta, \mathrm{ppm}: 166.8,164.0,153.0$ (4C), 138.4, 136.8 (2C), 135.9 (2C), 133.0, 131.3 (2C), 129.2 (2C), 112.8 (2C), 21.2; FT IR ( $\left.\mathrm{NaCl}, \mathrm{cm}^{-1}\right): 3036,1579,1554,1491$, 1482, 858, 775, 637; HRMS (ES TOF) calcd for $\mathrm{C}_{19} \mathrm{H}_{13} \mathrm{~N}_{4}(\mathrm{M}+$ $\mathrm{H})^{+}: 297.1135$, found 297.1129 (2.0 ppm).

\section{2,7-Diphenylpyrimido[4,5,6-gh]perimidine $(1 \mathrm{cc})^{11 b}$}

This material was obtained as a yellowish crystalline solid, $\mathrm{mp}$ over $300{ }^{\circ} \mathrm{C}, \quad R_{\mathrm{f}} 0.85 \quad(10 \% \quad$ EtOH/EtOAc); yield $113 \mathrm{mg}$ (0.32 mmol, 63\%) - via method B; ${ }^{1} \mathrm{H}$ NMR $\left(\mathrm{CDCl}_{3}\right) \delta$, ppm: 8.84 $(\mathrm{d}, J=8.5 \mathrm{~Hz}, 4 \mathrm{H}), 8.68(\mathrm{~s}, 4 \mathrm{H}), 7.63-7.52(\mathrm{~m}, 6 \mathrm{H}) ;{ }^{13} \mathrm{C} \mathrm{NMR}$ $\left(\mathrm{CDCl}_{3}\right) \delta$, ppm: 167.0 (2C), 152.3 (4C), 139.1 (2C), 135.2 (4C), 133.1 (2C), 131.3 (4C), 129.5 (4C), 113.0 (2C); FT IR ( NaCl, $\mathrm{cm}^{-1}$ ): 3045, 1573, 1561, 1499, 1485, 852, 770, 641; HRMS (ES TOF) calcd for $\mathrm{C}_{24} \mathrm{H}_{15} \mathrm{~N}_{4}(\mathrm{M}+\mathrm{H})^{+}:$359.1291, found 359.1301 (2.8 ppm).

\section{2-Benzylpyrimido[4,5,6-gh]perimidine (1ad)}

This material was obtained as a yellowish crystalline solid, $\mathrm{mp}$ over $300{ }^{\circ} \mathrm{C}, R_{\mathrm{f}} 0.65$ (10\% EtOH/EtOAc); yield $93 \mathrm{mg}$ (0.32 mmol, $63 \%)$ - via method A in reaction of $4 \mathrm{a}$ with $10 \mathrm{~d} ;{ }^{1} \mathrm{H} \mathrm{NMR}\left(\mathrm{CDCl}_{3}\right)$ $\delta$, ppm: $10.01(\mathrm{~s}, 1 \mathrm{H}), 8.51(\mathrm{~d}, J=9.9 \mathrm{~Hz}, 2 \mathrm{H}), 8.47(\mathrm{~d}, J=9.9 \mathrm{~Hz}$, 2H), 7.51 (d, $J=7.8 \mathrm{~Hz}, 2 \mathrm{H}), 7.35-7.32$ (m, 2H), 7.21, 7.23-7.19 $(\mathrm{m}, 1 \mathrm{H}), 4.23(\mathrm{~s}, 2 \mathrm{H}) ;{ }^{13} \mathrm{C} \mathrm{NMR}\left(\mathrm{CDCl}_{3}\right) \delta, \mathrm{ppm}: 163.2,157.9$, 152.3 (2C), 151.6 (2C), 139.7, 136.4 (2C), 134.5 (2C), 129.4 (2C), 128.6 (2C), 126.7, 115.2 (2C), 29.8; FT IR ( $\left.\mathrm{NaCl}, \mathrm{cm}^{-1}\right): 3047$, 1582, 1555, 1491, 1475, 863, 761, 633; HRMS (ES TOF) calcd for $\mathrm{C}_{19} \mathrm{H}_{13} \mathrm{~N}_{4}(\mathrm{M}+\mathrm{H})^{+}:$297.1135, found 297.1143 (2.7 ppm).

\section{2-Benzyl-7-methylpyrimido[4,5,6-gh]perimidine (1bd)}

This material was obtained as a yellowish crystalline solid, $\mathrm{mp}$ over $300{ }^{\circ} \mathrm{C}, \quad R_{\mathrm{f}} \quad 0.76 \quad(10 \%$ EtOH/EtOAc); yield $102 \mathrm{mg}$ $(0.33 \mathrm{mmol}, 66 \%)$ - via method A in reaction of $4 \mathrm{~b}$ with $10 \mathrm{~d} ;{ }^{1} \mathrm{H}$ NMR $\left(\mathrm{CDCl}_{3}\right) \delta$, ppm: $8.53(\mathrm{~s}, 4 \mathrm{H}), 7.52(\mathrm{~d}, J=7.8 \mathrm{~Hz}, 2 \mathrm{H}), 7.35-$ 7.32 (m, 2H), 7.21, 7.23-7.19 (m, 1H), 4.18 (s, 2H), 3.19 (s, 3H); ${ }^{13} \mathrm{C}$ NMR $\left(\mathrm{CDCl}_{3}\right) \delta$, ppm: 166.8 (2C), 152.1 (4C), 137.7, 135.4 (4C), 129.0 (2C), 128.2 (2C), 126.6, 111.4 (2C), 29.2, 26.6; FT IR $\left(\mathrm{NaCl}, \mathrm{cm}^{-1}\right): 3053,1574,1568,1483,1489,1351,1344,866$; HRMS calcd for $\mathrm{C}_{20} \mathrm{H}_{15} \mathrm{~N}_{4}(\mathrm{M}+\mathrm{H})^{+}: 311.1291$, found 311.1282 (2.9 ppm).

Reaction of $4 \mathrm{~b}$ with acetonitrile to intercept 2,7-dimethyl-1,8dihydropyrimido $[4,5,6-\mathrm{gh}]$ perimidine $(3 \mathrm{bb})$ (method $\mathrm{C}$ )

A mixture of 2-methyl-6,7-diaminoperimidine trihydrochloride (71 $\mathrm{mg}, 0.25 \mathrm{mmol}$ ) and polyphosphoric acid $\left(86 \% \mathrm{P}_{2} \mathrm{O}_{5}, 1.0 \mathrm{~g}\right)$ was vigorously stirred under argon atmosphere and dry acetonitrile ( $52 \mu \mathrm{L}, 41 \mathrm{mg}, 1.0 \mathrm{mmol}$ ) was injected in a single portion. The mixture was heated for $3 \mathrm{~h}$ at $100{ }^{\circ} \mathrm{C}$, and then poured into freshly distilled degassed water $(50 \mathrm{~mL})$, neutralized with aqueous ammonia, extracted with EtOAc $(5 \times 50 \mathrm{~mL})$, and concentrated under argon. Crude compound $\mathbf{3 b}$ was isolated as brownish-red solid, $\mathrm{R}_{\mathrm{f}} 0.10$ (EtOAc/EtOH $8: 1$ ), relatively stable in solid form stored under inert atmosphere, but quickly decomposing in solutions or upon contact with air. GC detection as well as mass-spectral characterization of this compound proved impossible due to very rapid oxidation into $\mathbf{1 b b}$ upon heating. Our attempt to measure of ${ }^{13} \mathrm{C}$ NMR spectrum also proved unfruitful, since this compound decomposes in solutions faster than it was necessary to accumulate sufficient number of scans for carbon spectrum. We were able to measure ${ }^{1} \mathrm{H}$ NMR spectrum (see ESI $\dagger$ for spectral chart). This experiment demonstrated, that $\mathbf{3 b b}$ exists in solution in $\mathrm{CDCl}_{3}$ as a mixture of equilibrating 1,8-dihydro- and 1,6-dihydro-tautomers along with minute amount of oxidized product $\mathbf{1 b b}$.

\section{Reaction of 2,7-dimethyl-1,8-dihydropyrimido[4,5,6-gh] perimidine (3bb) with nitroethane in PPA}

Compound $3 \mathbf{b b}(59 \mathrm{mg}, 0.25 \mathrm{mmol}$ ) obtained in the reaction of $\mathbf{4 b}$ and acetonitrile as described above (method $\mathrm{C}$ ) was stirred at $100{ }^{\circ} \mathrm{C}$ in $86 \%$ PPA (1.0 g) under argon atmosphere. Nitroethane (18 $\mu \mathrm{L}, 19 \mathrm{mg}, 0.25 \mathrm{mmol}, 1.00$ equiv.) was injected in a single portion and the stirring was continued for $3 \mathrm{~min}$, after which color of the reaction mixture changes from dark-red to green indicating the completion of the oxidation process. The postreaction work up and isolation of the product was carried out in the same way as described for method A. Compound $\mathbf{1 b b}$ (47 mg, $0.20 \mathrm{mmol}$, 80\%) was obtained as sole product. Physical and spectral properties of this material were identical to those described above for the sample obtained via method A.

\section{Acknowledgements}

This project received financial support from the Ministry of Education and Science of the Russian Federation (the Agreement number 02.a03.0008). Financial support from the Russian Foundation for Basic Research (grants \#16-03-00177a and 163300483 mol_a) is also gratefully acknowledged.

\section{Notes and references}

1 For reviews, see: (a) F. Würthner and R. Schmidt, ChemPhysChem, 2006, 7, 793-797; (b) J. E. Anthony, Chem. Rev., 2006, 106, 5028-5048; (c) J. Wu, W. Pisula and K. Müllen, Chem. Rev., 2007, 107, 718-747; (d) V. Coropceanu, J. Cornil, D. A. da Silva Filho, Y. Olivier, R. Silbey and J.-L. Bredas, Chem. Rev., 2007, 107, 926-952; (e) Y. Shirota and H. Kageyama, Chem. Rev., 2007, 107, 953-1010; (f) H. E. Katz and J. Huang, Annu. Rev. Mater. Res., 2009, 39, 71-92; (g) B. C. Thompson and J. M. J. Fréchet, Angew. Chem., Int. Ed., 2008, 47, 58-77; (h) J. E. Anthony, Angew. Chem., Int. Ed., 2008, 47, 452-483; (i) C. Wang, H. Dong, W. Hu, Y. Liu and D. Zhu, Chem. Rev., 2012, 112, 2208-2267.

2 See, for example: (a) P. Jonkheijm, N. Stutzmann, Z. Chen, D. M. de Leeuw, E. W. Meijer, A. P. H. J. Schenning and 
F. Würthner, J. Am. Chem. Soc., 2006, 128, 9535-9540; (b) H. Z. Chen, M. M. Ling, X. Mo, M. M. Shi, M. Wang and Z. Bao, Chem. Mater., 2007, 19, 816-824; (c) R. Schmidt, M. M. Ling, J. H. Oh, M. Winkler, M. Könemann, Z. Bao and F. Würthner, Adv. Mater., 2007, 19, 3692-3695; (d) R. Schmidt, J. H. Oh, Y.-S. Sun, M. Deppisch, A.-M. Krause, K. Radacki, H. Braunschweig, M. Könemann, P. Erk, Z. Bao and F. Würthner, J. Am. Chem. Soc., 2009, 131, 6215-6228; (e) H. Qian, W. Yue, Y. Zhen, S. Di Motta, E. Di Donato, F. Negri, J. Qu, W. Xu, D. Zhu and Z. Wang, J. Org. Chem., 2009, 74, 6275-6282; (f) X. Zhan, A. Facchetti, S. Barlow, T. J. Marks, M. A. Ratner, M. R. Wasielewski and S. R. Marder, Adv. Mater., 2011, 23, 268-284; $(g)$ H. C. Hesse, J. Weickert, C. Hundschell, X. Feng, K. Müllen, B. Nickel, A. J. Mozer and L. Schmidt-Mende, Adv. Energy Mater., 2011, 1, 861-869.

3 (a) S. C. Martens, L. Hahn, F. Lombeck, A. Rybina, H. Wadepohl and L. H. Gade, Eur. J. Org. Chem., 2013, 5295-5302; (b) S. Geib, S. C. Martens, U. Zschieschang, F. Lombeck, H. Wadepohl, H. Klauk and L. H. Gade, J. Org. Chem., 2012, 77, 6107-6116; (c) W.-C. Chen and I. Chao, J. Phys. Chem. C, 2014, 118, 20176-20183.

4 A. F. Pozharskii, V. N. Koroleva, I. V. Komissarov, I. T. Fillippov and I. V. Borovlev, Pharm. Chem. J., 1976, 10, 1613-1617.

5 Z. D. Wang, J. Eilander, M. Yoshida and T. Wang, Eur. J. Org. Chem., 2014, 7664-7674.

6 A. Ziesak, T. Wesp, O. Huebner, E. Kaifer, H. Wadepohl and H.-J. Himmel, Dalton Trans., 2015, 44, 19111-19125.

7 See, for recent examples: (a) A. V. Aksenov, N. A. Aksenov, D. S. Ovcharov, D. A. Aksenov, L. G. Voskressensky and M. Rubin, RSC Adv., 2016, 6, 82425-82431; (b) A. V. Aksenov, M. H. Magamadova, D. A. Lobach, I. V. Aksenova, I. V. Malikova and M. Rubin, Chem. Heterocycl. Compd., 2014, 50, 1298-1304; S. V. Shcherbakov, D. A. Lobach, M. Rubin and A. V. Aksenov, Chem. Heterocycl. Compd., 2014, 50, 757-760.

8 See, for example: (a) A. V. Aksenov, D. A. Aksenov, N. A. Orazova, N. A. Aksenov, G. D. Griaznov, A. De Carvalho, R. Kiss, V. Mathieu, A. Kornienko and M. Rubin, J. Org. Chem., 2017, 82, 3011-3018; (b) A. V. Aksenov,
A. N. Smirnov, N. A. Aksenov, I. V. Aksenova, J. P. Matheny and M. Rubin, RSC Adv., 2015, 5, 8647-8656; (c) A. V. Aksenov, A. N. Smirnov, N. A. Aksenov, I. V. Aksenova, A. S. Bijieva and M. Rubin, Org. Biomol. Chem., 2014, 12, 9786-9788; (d) A. V. Aksenov, A. N. Smirnov, N. A. Aksenov, I. V. Aksenova, L. V. Frolova, A. Kornienko, I. V. Magedov and M. Rubin, Chem. Commun., 2013, 49, 9305-9307.

9 A. V. Aksenov, A. S. Lyakhovnenko, T. S. Perlova and I. V. Aksenova, Chem. Heterocycl. Compd., 2011, 47, 916-917. 10 (a) A. V. Aksenov, N. A. Aksenov, A. S. Lyakhovnenko, A. N. Smirnov, I. I. Levina and I. V. Aksenova, Chem. Heterocycl. Compd., 2013, 49, 980-987; (b) A. V. Aksenov, A. S. Lyakhovnenko, N. T. Karaivanov and I. V. Aksenova, Chem. Heterocycl. Compd., 2010, 46, 1146-1147; (c) A. V. Aksenov, A. S. Lyakhovnenko, A. N. Spicin and I. V. Aksenova, Chem. Heterocycl. Compd., 2011, 47, 11801182; (d) A. V. Aksenov, N. A. Aksenov, A. E. Tsys', V. I. Goncharov and S. N. Ovcharov, Russ. Chem. Bull., 2013, 62, 1127-1128.

11 (a) A. V. Aksenov, N. A. Aksenov, O. N. Nadein and I. V. Aksenova, Synth. Commun., 2012, 42, 541-547; (b) A. V. Aksenov, N. A. Aksenov, O. N. Nadein and I. V. Aksenova, Chem. Heterocycl. Compd., 2011, 46, 14051406; (c) A. V. Aksenov, N. A. Aksenov, O. N. Nadein and A. E. Tsys, Chem. Heterocycl. Compd., 2010, 46, 1025-1026; (d) A. V. Aksenov, N. A. Aksenov, O. N. Nadein and I. V. Aksenova, Synlett, 2010, 2628-2630; (e) A. V. Aksenov, N. A. Aksenov, N. A. Orazova, D. A. Aksenov, M. V. Dmitriev and M. Rubin, RSC Adv., 2015, 5, 8484984855; $(f)$ N. A. Aksenov, A. V. Aksenov, O. N. Nadein, D. A. Aksenov, A. N. Smirnov and M. Rubin, RSC Adv., 2015, 5, 71620-71626.

12 A. V. Aksenov, A. N. Smirnov, N. A. Aksenov, A. S. Bijieva, I. V. Aksenova and M. Rubin, Org. Biomol. Chem., 2015, 13, 4289-4295.

13 (a) R. Sarkar and S. Mukherjee, Org. Lett., 2016, 18, 61606163; (b) M. S. Manna and S. Mukherjee, J. Am. Chem. Soc., 2015, 137, 130-133.

14 W. Will, Chem. Ber., 1895, 28, 2234-2235.

15 O. Dimroth and H. Roos, Liebigs Ann. Chem., 1927, 456, 177192. 